\title{
Crisis is a Gateway to Censored Information: The Case of Coronavirus in China
}

\author{
Keng-chi Chang William R. Hobbs Margaret E. Roberts \\ Zachary C. Steinert-Threlkeld
}

October 2, 2020

\begin{abstract}
Crisis and anxiety motivate people to track news closely. We examine the consequences of this increased motivation in authoritarian regimes that normally exert significant control over access to media. Using the case of the COVID-19 outbreak in China, we show that crisis spurs censorship circumvention to access international news and political content on websites blocked in China. Once individuals have circumvented censorship, they not only receive more information about the crisis itself, but the crisis becomes a gateway to unrelated information that the regime has long censored. Through this mechanism, crisis both increases attention to information relevant to individuals' current circumstances and incidentally increases access to information that the regime considers sensitive.
\end{abstract}

Media dependency theory predicts that during crises or uncertain time periods, people will rely more on mass media for information relevant to their own safety and spend more time seeking out information (Ball-Rokeach and DeFleur, 1976). Increased attention to media during crisis has been shown empirically in such varied cases as during democratization in Eastern Europe (Loveless, 2008), during the eruption of Mt. St. Helens (Hirschburg, Dillman and Ball-Rokeach, 1986), and immediately after the September 11 terrorist attacks (Althaus, 2002; Kim et al., 2004; Bar-Ilan and Echermane, 2005). Scholars who study crisis and anxiety in politics have suggested that increased attention to the media during crisis could present opportunities for large changes in opinion or political socialization in new democracies (Marcus and MacKuen, 1993; Loveless, 2008).

In this research note, we examine the effect of crisis on information seeking in highly censored environments. In these contexts, crisis increases attention to mass media and increases censorship evasion. In doing so, crisis increases attention to information relevant to individuals' current circumstances and also to unrelated information that the regime considers sensitive and has long been censored.

We illustrate this phenomenon through an in-depth study of the COVID-19 public health crisis in China. In January and February of 2020, COVID-19 cases in China were spiking, and fear and uncer- 
tainty about the coronavirus within China was widespread. Using a variety of measures of circumvention of the Great Firewall, we show large and sustained impact of the crisis on circumvention of censorship in China. We find the largest effect in areas most affected by the crisis - those closer to the crisis epicenter in Wuhan. In addition, information seeking across the Great Firewall extended beyond information about the virus to information the Chinese Communist Party (CCP) has long deemed sensitive, including information about historical political events and leaders that are highly censored in China.

To draw a comparison, we investigate the same patterns in other countries with no censorship or less sophisticated censorship regimes that experienced similar levels of virus cases and crisis soon after China. As expected, we find higher levels of engagement with online news media generally, though there is not a similar pattern of users seeking out information about historical events or leaders unrelated to the crisis. This difference implies that while information seeking increases during crisis under all forms of governance, the added gateway to previously unknown and sensitive content for those in authoritarian contexts may make crises additionally sensitive for autocracies.

\section{Crisis is a Gateway to Censored Information}

In many authoritarian countries, traditional and online media limit access to information (Morozov, 2011; MacKinnon, 2012; Deibert et al., 2011; Sanovich, Stukal and Tucker, 2018). While this control is imperfect, studies have shown that media control in autocracies has large effects on the opinions of the general public and the resilience of authoritarian regimes (Stockmann and Gallagher, 2011; Enikolopov, Petrova and Zhuravskaya, 2011; Adena et al., 2015; Yanagizawa-Drott, 2014; Stockmann, 2012; Huang, 2015; Roberts, 2018), even though there are moments when it can backfire (Pan and Siegel, 2020; Jansen and Martin, 2003; Nabi, 2014; Hassanpour, 2014; Hobbs and Roberts, 2018; Gläßel and Paula, 2019; Boxell and Steinert-Threlkeld, 2019). Evidence from China suggests that media control may be effective in part because individuals generally do not expend significant energy to find censored or alternative sources of information. ${ }^{1}$

While many have studied the impact of information control in normal times in authoritarian regimes, less is known about information seeking during crisis. In democracies, information seeking intensifies during crisis, increasing consumption of mass media. Ball-Rokeach and DeFleur (1976)'s model of

\footnotetext{
${ }^{1}$ Stockmann (2012) provides evidence that consumers of newspapers in China are unlikely to go out of their way to seek out alternative information sources. Chen and Yang (2019) provided censorship circumvention software to college students in China, but found that students chose not to evade the Firewall unless they were incentivized monetarily. Roberts (2018) provides survey evidence that very few people choose to circumvent the Great Firewall because they are unaware that the Firewall exists or find evading it difficult and bothersome.
} 
dependency on the media suggests that audiences are more reliant on mass media during certain time periods, especially when there are high levels of conflict and change in society. These findings are largely consistent with research on emotion in politics, which concludes that political situations that produce anxiety motivate people to seek out information (Marcus, Neuman and MacKuen, 2000). While in normal times information seeking is strongly influenced by pre-existing beliefs, several studies have suggested that crisis can cause people to seek out information that might contradict their partisanship or worldview (Marcus and MacKuen, 1993; MacKuen et al., 2010), although they may pay disproportionate attention to threatening information (Albertson and Gadarian, 2015).

Similar patterns may exist in authoritarian environments. Because the government controls mass media, citizens aware of censorship may not only consume more mass media that is readily available during crises, but also seek to circumvent censorship or seek out alternative sources of information that they may normally not access. For example, during the SARS crisis in China in 2003, Tai and Sun (2007) find that people in China turned to SMS and the Internet to gather and corroborate information they received from mass media. Cao (2020) shows an increase in censorship evasion and use of Twitter from China during "regime-worsening" events, such as worsening of trade relations between the U.S. and China and the removal of Presidential term limits in the constitution in 2018.

Evasion of censorship during crisis could be particularly dangerous for autocracies because it might give information to consumers not just about the crisis itself, but also about information that has long been censored by the regime. This phenomenon, a "gateway effect," has been shown in the context of censorship of entertainment (Hobbs and Roberts, 2018), where consumers are motivated to circumvent censorship for one reason, but in doing so are exposed to unrelated sensitive political information. Crisis might lead to a similar, or even more pronounced "gateway effect" because people may be more likely to seek out political information during crisis than those seeking to circumvent censorship for entertainment purposes. Anxiety about the epidemic could lead consumers of information to explicitly seek out information that has long been censored to better understand the trustworthiness of their government.

\section{The COVID-19 Crisis in China}

On December 31, 2019, officials in Wuhan, China confirmed that a pneumonia-like illness had infected dozens of people. By January 7, 2020, Chinese health officials had identified the disease - a new type of coronavirus called novel coronavirus, later renamed COVID-19. By January 10, the first death from COVID-19 was reported in China, and soon the first case of COVID-19 was reported outside of China, 
in Thailand. As of August 2020, COVID-19 has infected over 91,000 people in China with over 4,500 deaths, and over 17 million people worldwide with over 650,000 deaths. $^{2}$

While initial reports of COVID-19 were delayed by officials in Wuhan, ${ }^{3}$ Chinese officials took quick steps to contain the virus after it was officially identified and the first deaths reported. On January 23, 2020 , the entire city was placed under quarantine - the government disallowed transportation to and from the city and placed residents of the city on lockdown. ${ }^{4}$ The next day, similar restrictions were placed on 9 other cities in Hubei province. ${ }^{5}$ While Hubei province and Wuhan were most affected by the outbreak, cities all over China were subject to similar lockdowns. By mid-February, about half of China -780 million people - were living under some sort of travel restrictions. ${ }^{6}$ Between January 10 and February 29, 2020, 2,169 people in Wuhan died of the virus. ${ }^{7}$

\section{The Effect of Crisis on Information Seeking and Censorship Circum- vention}

We use digital trace data to understand the effect of the COVID-19 crisis on information seeking. Table 1 summarizes the empirical tests we conduct in this paper. In the first subsection, we show that the crisis increased the popularity of virtual private network (VPN) applications, which are necessary to jump the Great Firewall, downloaded on iPhones in China. We also show that the crisis expanded the number of Twitter users in China, which has been blocked by the Great Firewall since 2009. The crisis further increased the number of page views of Chinese language Wikipedia, which has been blocked by the Great Firewall since 2015. The second subsection shows that the areas more affected by the crisis - such as Wuhan and Hubei Province - were more likely to see increases of circumvention.

The third subsection shows that the increase in circumvention caused by the crisis also expanded

\footnotetext{
${ }^{2}$ Source: New York Times, July 31, 2020. https://www.nytimes.com/interactive/2020/world/ coronavirus-maps.html

${ }^{3}$ Chris Buckley and Steven Lee Myers. "As New Coronavirus Spread, China's Old Habits Delayed Fight.” The New York Times. February 1, 2020. https://www.nytimes.com/2020/02/01/world/asia/china-coronavirus.html Last accessed: 2020-09-14.

${ }^{4}$ Amy Qin and Vivian Wang. "Wuhan, Center of Coronavirus Outbreak, Is Being Cut Off by Chinese Authorities," The New York Times. January 22, 2020. https://www.nytimes.com/2020/01/22/world/asia/china-coronavirus-travel. html Last accessed: 2020-09-14.

${ }^{5}$ James Griffiths, Tara John and Steve George. "Unprecedented lockdown on 10 cities and 30 million people." CNN. January 24, 2020. https://www. cnn.com/asia/live-news/coronavirus-outbreak-hnk-intl-01-24-20/h_ 2587b2ec049c50eb87e75f321f40d2b4 Last accessed: 2020-09-14.

${ }^{6}$ James Griffiths and Amy Woodyatt. "780 million people in China are living under travel restrictions due to the coronavirus outbreak." CNN. February 16, 2020. https://www.cnn.com/2020/02/16/asia/ coronavirus-covid-19-death-toll-update-intl-hnk/index.html Last accessed: 2020-09-14.

${ }^{7}$ Pam Belluck. "Coronavirus Death Rate in Wuhan Is Lower than Previously Thought, Study Finds." New York Times. March 19, 2020. https://www.nytimes .com/2020/03/19/health/wuhan-coronavirus-deaths .html Last accessed: 2020-09-14.
} 
access to information that the Chinese government censors. On Twitter, blocked Chinese language news organizations and exiled dissidents disproportionately increased their followings from mainland China users. On Wikipedia, sensitive pages such as those pertaining to Chinese officials, sensitive historical events, and dissidents showed large increases in page views due to the crisis. Last, the fourth subsection shows that these dynamics do not occur on Wikipedia in countries with similar crisis, but where Wikipedia is uncensored.

Table 1: Empirical Tests

Question Test

1. Do individuals circumvent censorship more VPN ranking; increased use of blocked services; during crisis?

2. Do individuals access crisis information? new Twitter users.

\section{land China followers for certain account types.}

3. Do individuals access non-crisis sensitive information?

Wikipedia traffic about current leaders; new main4. Do these same dynamics occur in democracies
and less censored environments?
Wikipedia traffic to blocked pages; new mainland China followers for activists and foreign political figures.

Wikipedia page views in Germany, Italy, Iran, and Russia.

\subsection{Crisis Increased Censorship Circumvention}

We show that censorship circumvention increased in China as a result of the crisis using data from application analytics firm AppAnnie, which tracks the popularity of iPhone application downloads in China. While most VPN applications are blocked from the iPhone Apple Store, we identified one still available. Around the time of the Hubei lockdown, its rank popularity increased significantly and maintained that ranking (top-left panel of Figure 1). To protect the application and its users, we are not disclosing its name or the exact ranking, though results are available for review upon request.

Concurrent with the increase in popularity of the VPN application is a sudden increase in popularity of Facebook, Twitter, and Wikipedia applications, as Figure 1 shows. These increases indicate that those jumping the Firewall as a result of the crisis were engaging in part with long blocked websites in China - Twitter and Facebook have been blocked since 2009 and Chinese language Wikipedia since 2015.

This finding is consistent with data we collected directly from Twitter and Wikipedia. Using Twitter's POST statuses/filter endpoint, we identify $1,448,850$ tweets (101,553 accounts) from mainland China from December 1, 2019 until June 30, 2020. The left panel of Figure 2 shows the number of geolocating users in China posting in Chinese in the time period of interest. Immediately following the lockdown, Chinese language accounts geolocating to China increased 1.4 fold, and this effect persisted throughout the following months. The right panel of Figure 2 shows that the crisis also coincided with increases of 

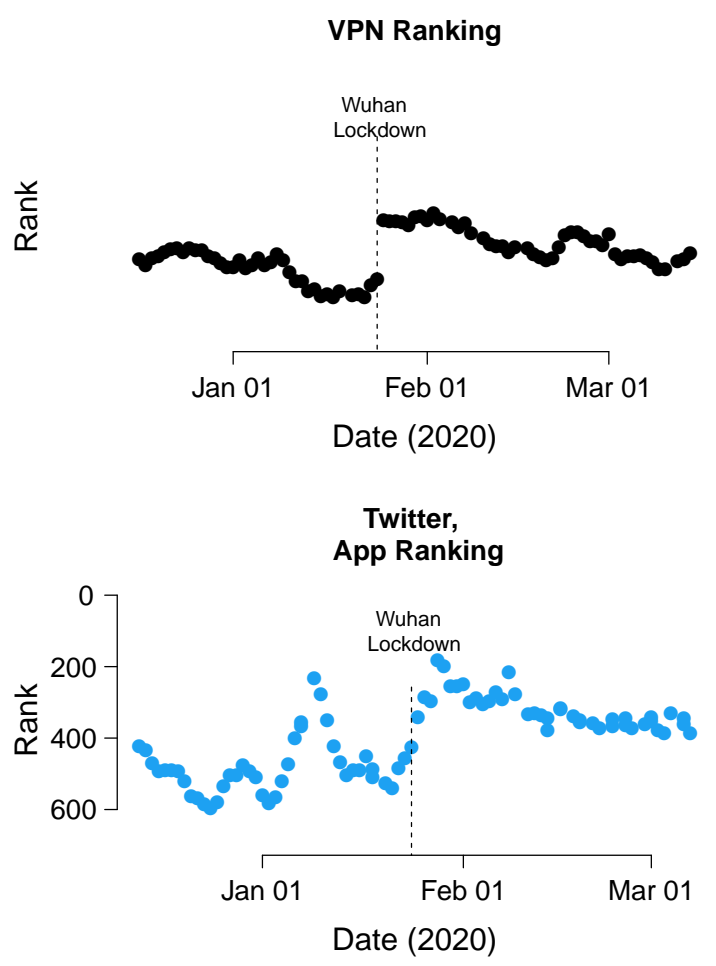
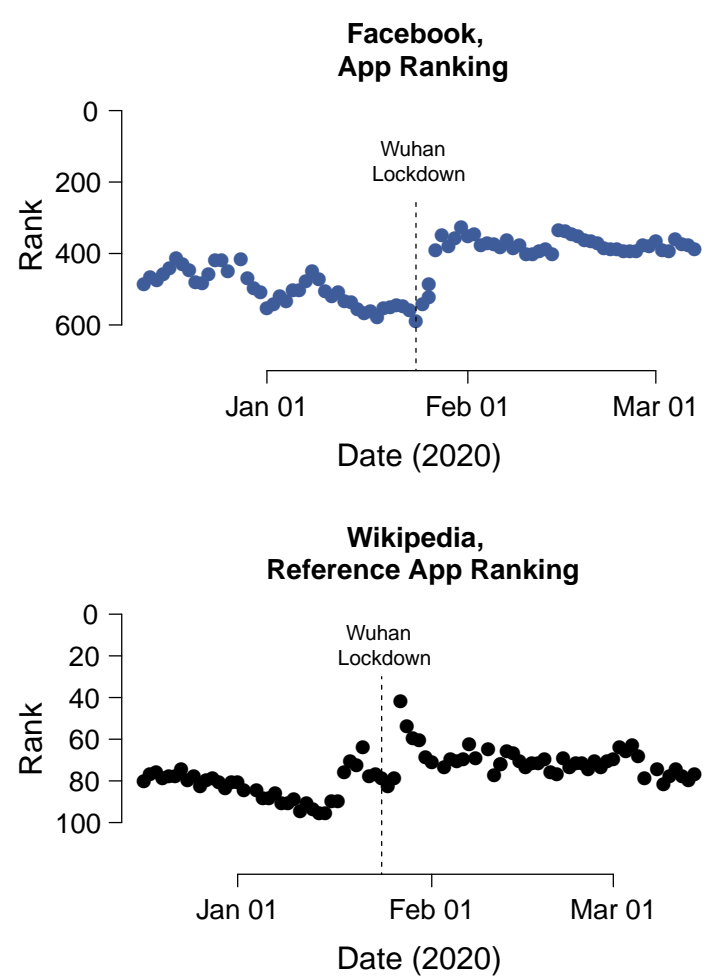

Figure 1: Rank of iPhone Application Facebook, Twitter, and Wikipedia, Source: App Annie Note: The top-left panel of this figure intentionally omits the name of the VPN app and its precise ranking.

new users, indicating that increases are due to new users and not dormant ones reactivating. ${ }^{8}$

Data from Wikipedia on the number of views of Wikipedia pages by language matches the App Annie and Twitter patterns. ${ }^{9}$ We measure the total number of views for Chinese language Wikipedia by day from before the coronavirus crisis to the time of writing. Figure 3 reveals large and sustained increases in views of Chinese language Wikipedia, beginning at the Wuhan lockdown and continuing above preCOVID levels through May 2020. Views of all Wikipedia pages in Chinese increased by around 10\% during lockdowns and by around $15 \%$ after the first month of lockdown. This increase persisted long after the decline of coronavirus contagion. In absolute terms, the total number of page views increases from around 12.8 million views per day in December 2019, to 13.9 million during the lockdown period (January 24 through March 13), and up to 14.7 million views per day from mid-February through the end of April.

\subsection{Increases in Circumvention Occurred Throughout China}

Whereas the data from AppAnnie and Wikipedia cannot distinguish between circumvention patterns within China, the geo-location in the Twitter data enables the examination of subnational variation. Cir-

\footnotetext{
${ }^{8}$ Section S2 provides more detail, and Figure A1 shows trends per province.

${ }^{9}$ This page view data is publicly available: https://dumps.wikimedia.org/other/pagecounts-ez/merged/
} 
Figure 2: (Left) Number of Unique Geo-Locating Users in China Posting in Chinese. (Right) The Fraction of Active Users Who Joined Twitter in the Last 30 Days.
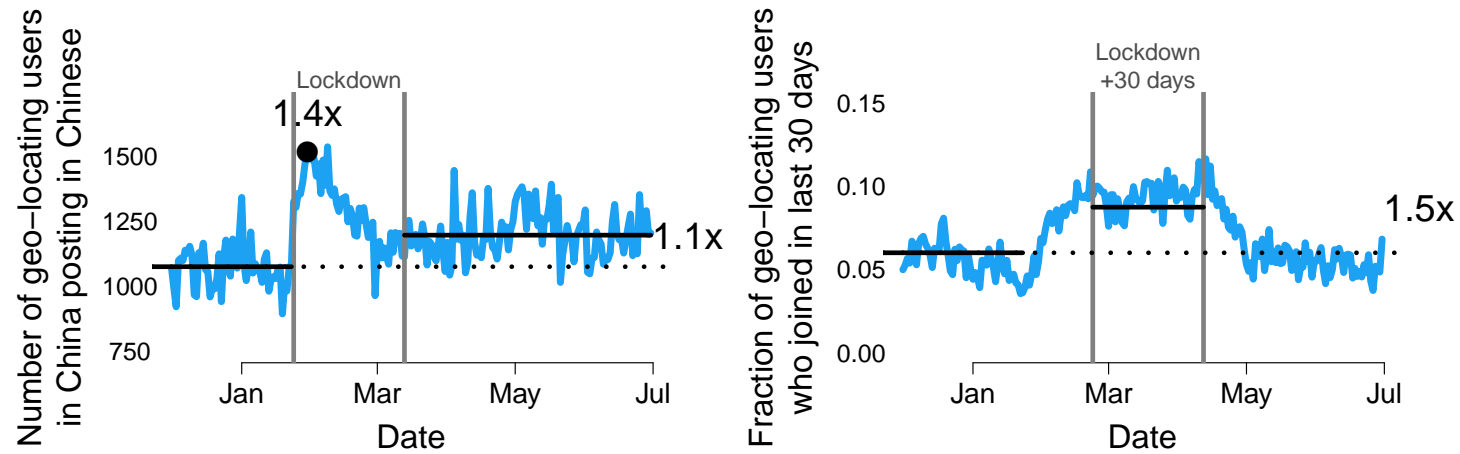

Note: These figures display unique users and unique users who signed up within the last 30 days. The decline in 'new' users after the end of lockdown in the right panel is driven by a decline in new sign-ups after lockdown easing, rather than lockdown users leaving the site (they are no longer considered new after 30 days).

\section{ZH: Change in Page Views per Day}

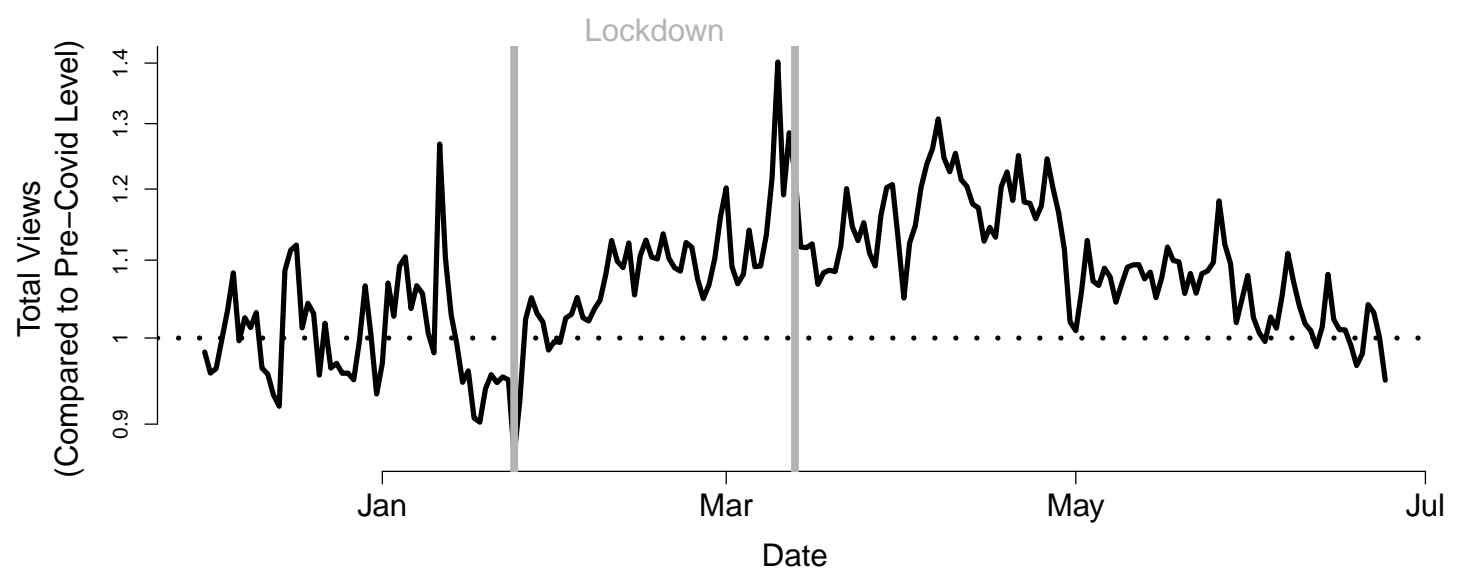

Figure 3: Views of Wikipedia Pages in Chinese

Note: This figure shows the ratio of total daily views of Wikipedia pages in Chinese compared to December 2019 views (12.7 million views per day in December 2019). The beginning of the Hubei lockdown and the first relaxation of lockdown in Hubei are indicated in gray.

cumvention occurred in provinces throughout China as a result of the Wuhan lockdown; Hubei, the most impacted province, experienced the most sustained increase in geolocated users.

Figure 4 measures the initial increase of Twitter volume on January 24, 2020, the day after Wuhan's lockdown and the start of lockdown in twelve other cities in Hubei, in comparison to the average from December 1, 2020 to January 22, 2020 in each province in China (the $\mathrm{x}$-axis). The $\mathrm{y}$-axis measures how sustained the increase was - the ratio of Twitter volume 30 days after the quarantine to the baseline before the outbreak. Hubei is in the top-right corner of the plot: Twitter volume there doubled in comparison to the previous baseline, and the doubling persisted 30 days after the crisis. ${ }^{10}$ These estimates are drawn

\footnotetext{
${ }^{10}$ While almost all provinces experience a sustained increase in Twitter volume, Beijing and Shanghai have an overall de-
} 
Figure 4: Increases in Geo-Located Twitter Activity by Province (modeled)

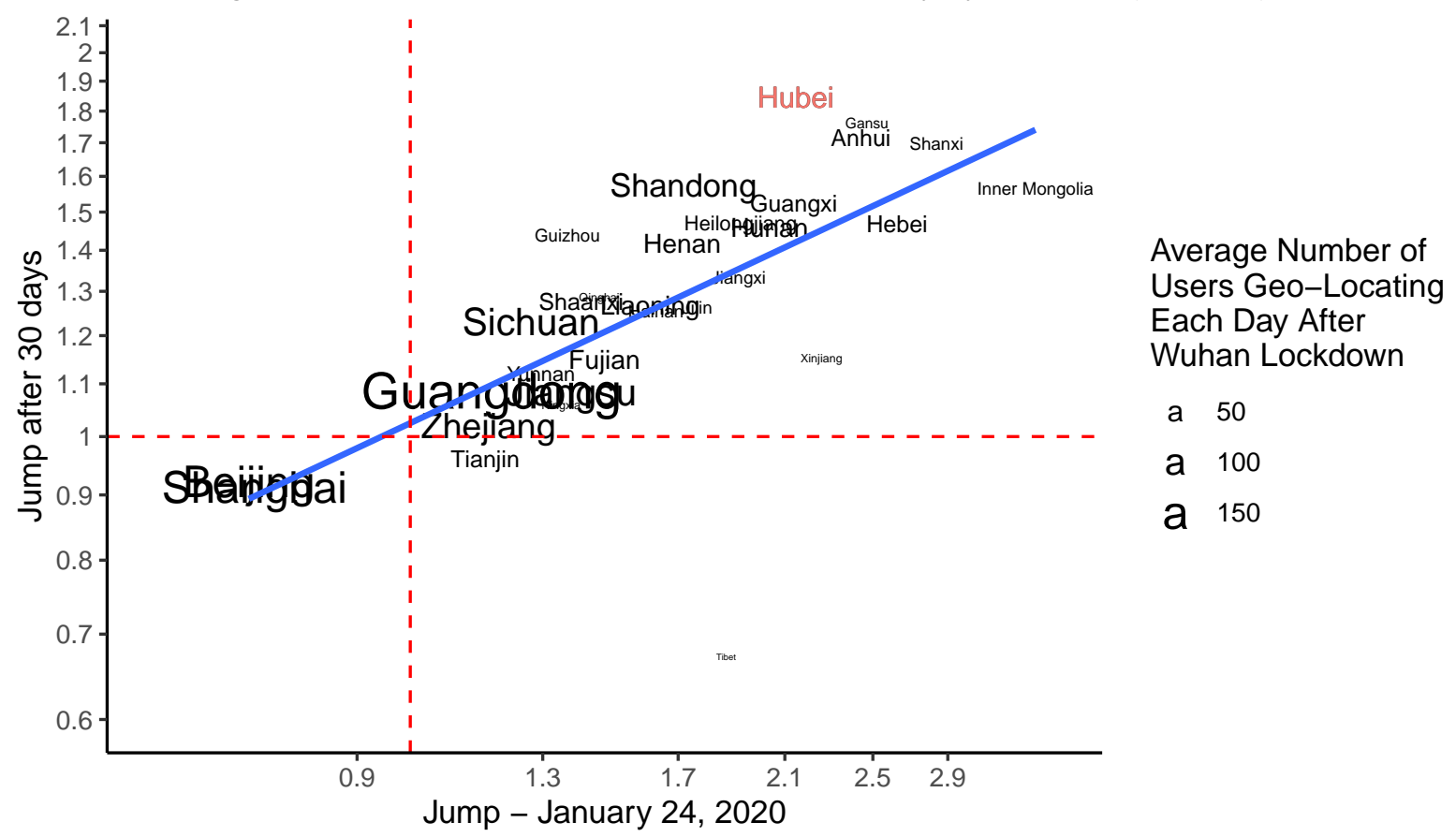

Note: This figure shows the increase in geo-located Twitter users compared to the average number of geo-located Twitter users in a province before the Hubei lockdown. Estimates for 30 days after and day of lockdown are drawn from a five term polynomial regression on the number of unique geo-located Twitter users per day after the lockdown. These province-by-province polynomials are displayed over the raw data in Figure S1.

from polynomial models fit to the daily number of users per province - Figure A1 in the appendix displays the modeled lines over the raw data for each province.

\subsection{Crisis Provided a Gateway to Censored Political Information}

In this section, we examine how the crisis impacted what content Twitter users from mainland China and users of Chinese language Wikipedia were consuming. Both Twitter and Wikipedia facilitate access to a wide range of content, not just information sensitive to the Chinese government. New users of Twitter from China might follow Twitter accounts producing entertainment or even Twitter accounts of Chinese state media and officials, who have become increasingly vocal on the banned platform. ${ }^{11}$ New users of Wikipedia might only seek out information about the virus and not about politics. If the crisis produced a gateway effect, we should see increases in consumption of sensitive political information unrelated to the crisis.

crease in Twitter volume after the outbreak. We suspect many Twitter users in Beijing and Shanghai left those cities during the outbreak.

${ }^{11}$ Laura Zhou. "Chinese officials have finally discovered Twitter. What could possibly go wrong?" South China Morning Post. August 4, 2019. scmp.com/news/china/diplomacy/article/3021310/ chinese-officials-have-finally-discovered-twitter-what-could Last accessed: 2020-09-14. 


\subsubsection{What types of Twitter accounts did mainland Twitter users start to follow as a result of the crisis?}

We use data from Twitter to examine what types of accounts received the largest increases in followers from China due to the crisis. First, we identify accounts that are commonly followed by Chinese Twitter users. To do this, we randomly sampled 5,000 users geolocated to China. For each of these users, we gathered the entire list of whom they follow, their Twitter "friends." From these 1,818,159 friends, we extracted the 5,000 most common accounts. ${ }^{12}$ Section $\mathrm{S} 2$ provides more detail.

We assigned each of these 5,000 popular accounts into one of six categories: 1) international sources of political information, including international news agencies; 2) Chinese citizen journalists or political commentators, which include non-state media discussions of politics within China; 3) activists, or accounts disseminating information about politics in the U.S., Taiwan, or Hong Kong; 4) accounts disseminating pornography; 5) state media and political figures; and 6) entertainment or commercial influencers. Categories 1, 2, and 3 are accounts that might distribute information sensitive to the Chinese government, such as international media blocked by the Great Firewall (e.g. New York Times Chinese and Wall Street Journal Chinese); Chinese citizen journalists and political commentators such as the famous Chinese blogger Han Han and currently detained blogger Yang Hengjun; and political activists such as free speech advocate Wen Yunchao and Wu'er Kaixi, former student leader of the 1989 Tiananmen Square Protests. Accounts in Category 4 are pornography, which we consider sensitive because it is generally censored by the Chinese government, but not politically sensitive like Categories 1-3. Accounts in Category 5 include accounts linked to the Chinese government, including the government's news mouthpieces Xinhua News and People's Daily, as well as the Twitter accounts of Chinese embassies in Pakistan and Japan. Category 6 is also not sensitive, as these accounts mostly do not tweet about politics, but instead are entertainment or commercial accounts or accounts of non-political individuals.

We want to understand how the coronavirus crisis affected the followings of each of the categories of popular Chinese language accounts, and in particular, compare how the crisis affected the followings of categories 1-3 to those in categories 5 and 6 . We therefore downloaded all accounts that began following these popular accounts after November $1,2019 .{ }^{13}$ We then use the location field to identify which of these 38,050,454 followers are from mainland China or Hong Kong (Section S2 explains.)

\footnotetext{
${ }^{12}$ We selected only accounts that were Chinese language accounts or had Chinese characters in their name or description field to ensure that we were studying relevant accounts: those disseminating information easily accessible to most Chinese users.

${ }^{13}$ The majority of the 5,000 accounts were pornography. Therefore, because of downloading constraints, we downloaded all new followers of non-pornography accounts and all new followers of a random selection of 200 pornography accounts. This sampling allows us to estimate the impact of the coronavirus on category 4 while decreasing our requests to the Twitter API.
} 
Because Twitter returns following lists in reverse chronological order, we can infer when an account started following another account (Steinert-Threlkeld, 2017). For the accounts in the six categories, we compare the increase in followers from mainland China to the increase in followers from Hong Kong accounts relative to their December 2019 baselines. ${ }^{14}$ The ultimate quantity of interest is the ratio of these two increases. If the ratio is greater than one, then the increase in following relationships is more pronounced among mainland Twitter users as compared to those from Hong Kong.

Figure 5 shows this ratio by category-day. Relative to Hong Kong, the crisis in mainland China inspired disproportionate followings of international news agencies, Chinese citizen journalists, activists, and pornography accounts - all information considered sensitive that has long been censored. In comparison, there is only a small increase in mainland followers of Chinese state media and political figures during the lockdown period and a slight decrease for non-political bloggers and entertainers. Figure 6 reports the regression estimate for the relative ratio of number of new followers (akin to a difference-indifferences design with Hong Kong as control group and December 2019 as pre-treatment period). The result is the same.

We then demonstrate that the result does not depend on the choice of comparison group and that the relative increase starts no earlier than Wuhan lockdown. Figure A2 in Section S2 conducts a placebo test by running weekly regressions, showing that the relative increase in followers in China starts precisely during the week of lockdown. Figures A3, A4, and A5 show that the results hold with alternative comparison groups such as overseas Chinese in Taiwan and the United States. Hence, the result is not driven by Hong Kong-specific news cycles. ${ }^{15}$ Table A1 shows accounts in each category with the greatest gain in relative followers. The result is not driven only by a few accounts.

\subsubsection{What types of Chinese language Wikipedia pages received the most attention?}

To better understand patterns of political views in the Wikipedia data, we leverage existing lists to categorize the Chinese language Wikipedia views into three different categories: 1) Wikipedia pages that were selectively blocked by the Great Firewall ${ }^{16}$ prior to Wikipedia's move to https (after which all of Wikipedia was blocked), 2) pages that describe high level Chinese officials (using offices listed in the CIA World Factbook ${ }^{17}$ ), and 3) historical leaders of China since Mao Zedong. Whereas we would expect

\footnotetext{
${ }^{14}$ Hong Kong is chosen because it is part of the PRC, but is not affected by the Firewall.

${ }^{15}$ The main caveat is that users in Taiwan and US are less likely than Hong Kong users to seek out information from Chinese state media or government officials.

${ }^{16}$ https : //www . greatfire.org/ maintains a list of websites censored by the Great Firewall.

${ }^{17} \mathrm{We}$ use this list for ease of comparisons with other countries and remove the Ambassador to the United States
} 
Figure 5: Increases in Twitter Followers from China vs Hong Kong By Category

New Followers Compared to Baseline, China / Hong Kong
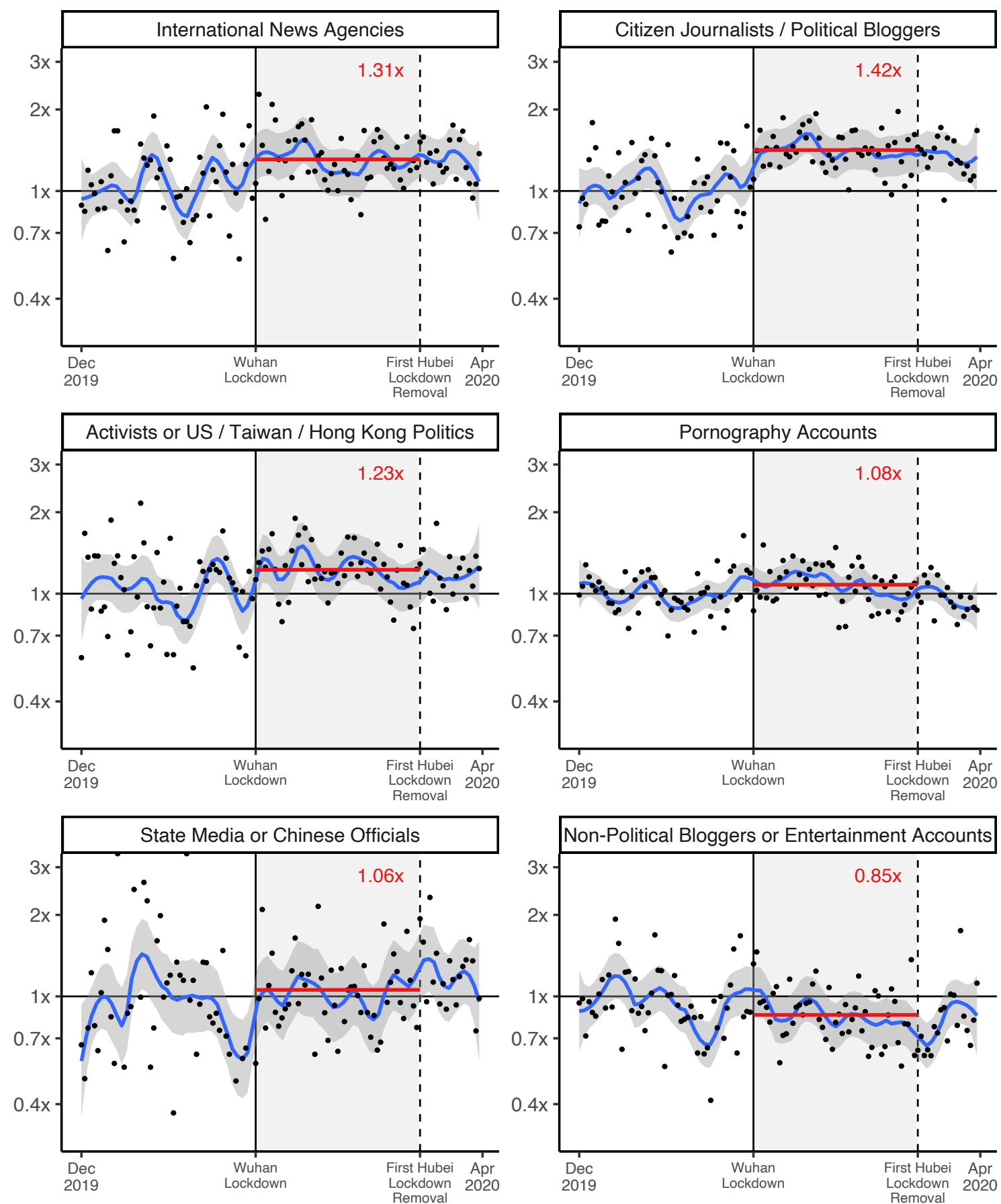

Note: Gain in followers from mainland China compared to Hong Kong across six types of popular accounts, relative to December 2019 trends. Ratios here approximate the incidence rate ratios estimated in the models for Figure 6. A value greater than 1 means more followers than expected from mainland China than from Hong Kong. Accounts creating sensitive, censored information receive more followers than expected once the Wuhan lockdown starts. Accounts that are not sensitive or censored, such as state media or entertainment, do not see greater than expected increases. 
Figure 6: Increases in Twitter Followers China vs Hong Kong By Category (Regression Estimate)

Relative Size of New Followers, China / Hong Kong

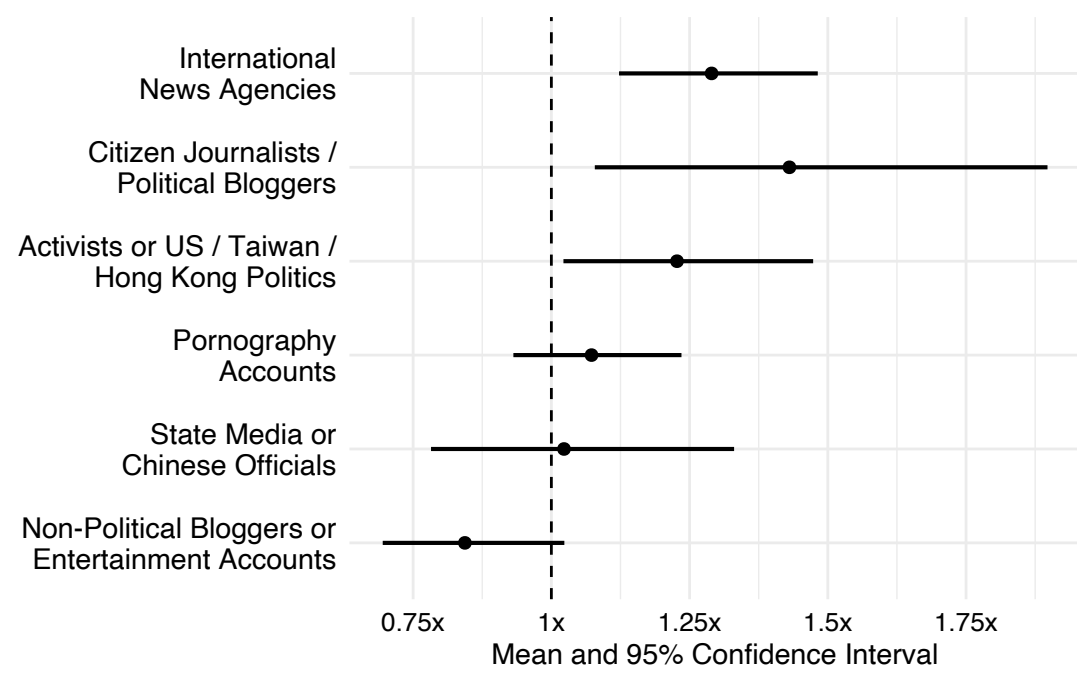

Note: Incidence rate ratios shown above are from negative binomial regressions of number of new followers on the interaction between indicator variables for 'in lockdown period' and 'in mainland China', with December 2019 as control period and Hong Kong as control group.

that a crisis in any country should inspire more information seeking about current leaders in Category 2 , only if crisis created a gateway to historically sensitive information would we expect proportional increases in information seeking about historical leaders in Category 3 or information about sensitive events that were selectively blocked by the Great Firewall on Wikipedia prior to 2015 in Category 1.

Figure 7 shows the increase in page views for each of these categories on Chinese Wikipedia relative to the rest of Chinese language Wikipedia. We find that the lockdown not only increased views of current leaders (purple), but also views of historical leaders (yellow) and views of pages selectively blocked by the Great Firewall (red). Tables A2 and A3 show specific pages disproportionately affected by the increase in views of Wikipedia. While pages related to coronavirus experienced a jump in popularity, other unrelated sensitive pages including the "June 4 Incident," "Ai Weiwei," and "New Tang Dynasty Television" (a television broadcaster affiliated with Falun Gong) also experienced an increase in page views.

\subsection{Comparison with Other Countries Affected by the Crisis}

Since information seeking during crisis is common to all countries, we investigate Wikipedia data from other countries affected by the crisis. We show that the gateway effect of crisis on historically sensitive

from each list. China's list is available here (and there are links to leaders of other countries on the same page): https://www.cia.gov/library/publications/resources/world-leaders-1/CH.html, excluding Hong Kong and Macau. For each individual on these lists, we checked that the individual was still in office in February 2020, and updated the officeholder if they were not. 


\section{ZH: Page Views by Category}

Lockdown

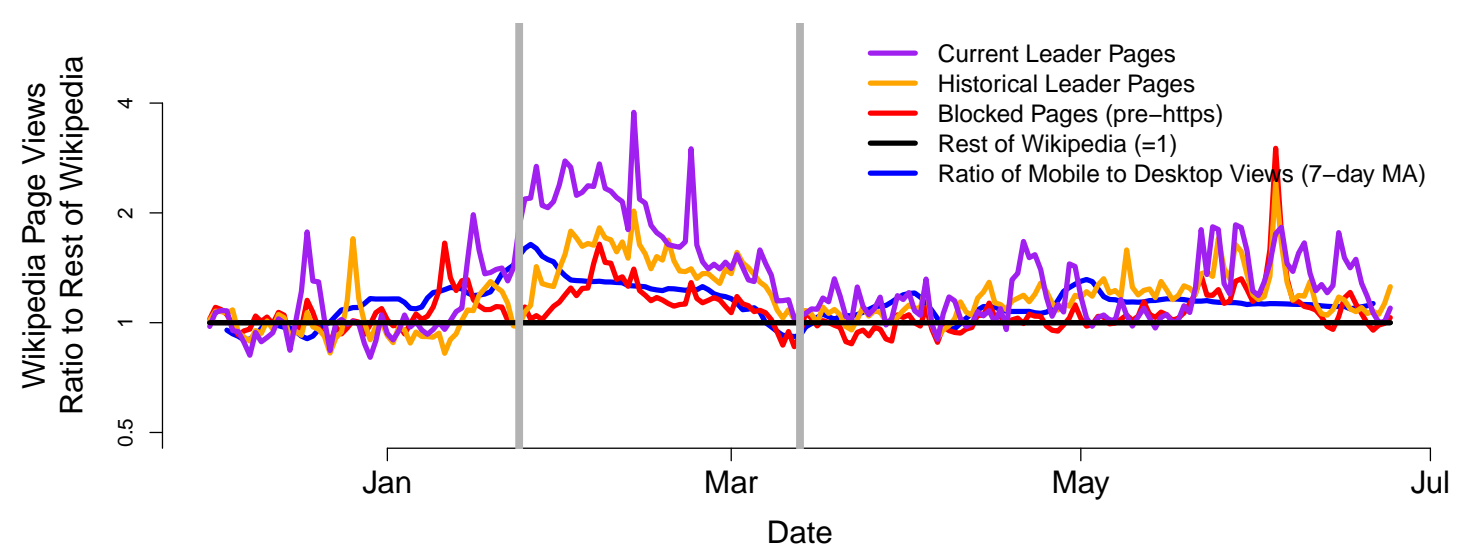

Figure 7: Views of Blocked, Current Leader, and Historical Leader Wikipedia Pages in Chinese. Note: Vertical lines indicate the start and end of the lockdown period in Hubei Province.

information is unique to the currently censored webpages in China. For comparison, we focus on Iran, another authoritarian country affected by COVID-19 that used to censor Wikipedia, but does not any longer, and Russia, an authoritarian country that does not censor Wikipedia. We also show data from democracies without censorship affected by the COVID-19 crisis, Italy and Germany. ${ }^{18}$

To make the comparison, we use the same offices listed in the CIA World Factbook to create lists of current leaders from these three countries, and create lists of historical leaders using de facto country leaders since World War II (see Table A4 in the appendix for a list of these titles and offices). All three of these countries were affected by the crisis in late February or early March and two of the countries - Italy and Iran - imposed lockdowns similar to that in Wuhan, China. Therefore, we expect increases in information seeking for current leaders, as citizens begin to pay more attention to current politics as the crisis hits. However, none of these countries block Wikipedia. Because of this, we expect that information seeking about the current crisis will not act as a gateway to information about historical events or controversies, as these pages are always available to the public.

Table 2 shows these results. While overall Wikipedia views and page views of current leaders increase in three out of four comparison countries, only in China do historical leaders increase disproportionately and consistently throughout the whole time period. That is, we see an overall effect on information-seeking throughout the world, including for historical leaders; in China, we see larger increases for historical leaders compared to Wikipedia page views in general. Further, we obtain lists of

\footnotetext{
${ }^{18}$ Citizens in each of these countries speak languages relatively specific to their country, and therefore we expect most of the page views of Italian, German, Persian, and Russia Wikipedia to originate in Italy, Germany, Iran, and Russia respectively.
} 
Wikipedia pages that were previously censored by Iran (Nazeri and Anderson, 2013). Unlike China, these pages can now be accessed without restriction in Iran and we do not see increased attention to these pages during the crisis. The small increases in historical political leader page views in German and Italian did not correspond with the start of the COVID-19 crisis or their respective lockdowns (figures at bottom of Table 2).

Table 2: During the lockdown period, Wikipedia views in Chinese increased relative to overall views for politically sensitive Wikipedia pages and political leader pages, as well as for historical political leaders.

\begin{tabular}{|c|c|c|c|c|}
\hline $\begin{array}{r}\text { Change: } \\
\text { Language }\end{array}$ & Overall & $\begin{array}{c}\text { Blocked } \\
\text { relative to overall: }\end{array}$ & Leaders & Historical Leaders \\
\hline \multirow[t]{3}{*}{ Chinese } & 1.09 & 1.15 & 1.86 & 1.42 \\
\hline & $(1.05-1.12)$ & $(1.09-1.22)$ & $(1.67-2.07)$ & $(1.32-1.52)$ \\
\hline & $<0.001$ & $<0.001$ & $<0.001$ & $<0.001$ \\
\hline \multirow[t]{3}{*}{ Persian } & $-\overline{1} . \overline{4} \overline{2}^{-}$ & $0 . \overline{84}$ & $\overline{0} . \overline{9} \overline{-}$ & $0 . \overline{8}$ \\
\hline & $(1.37-1.46)$ & $(0.79-0.89)$ & $(0.80-1.05)$ & $(0.75-0.90)$ \\
\hline & $<0.001$ & $<0.001$ & 0.20 & $<0.001$ \\
\hline \multirow[t]{3}{*}{ Russian } & 1.23 & & 1.73 & 0.90 \\
\hline & $(1.18-1.28)$ & & $(1.48-2.02)$ & $(0.82-0.99)$ \\
\hline & $<0.001$ & & $<0.001$ & 0.03 \\
\hline \multirow[t]{3}{*}{ German } & $-\overline{1} \overline{1} \overline{6}$ & & $\overline{2} . \overline{3} \overline{6}$ & $-1 . \overline{1}^{-}$ \\
\hline & $(1.12-1.20)$ & & $(2.02-2.76)$ & $(1.05-1.40)$ \\
\hline & $<0.001$ & & $<0.001$ & 0.01 \\
\hline \multirow[t]{3}{*}{ Italian } & 1.47 & & 3.29 & 1.17 \\
\hline & $(1.40-1.53)$ & & $(2.72-4.00)$ & $(1.02-1.34)$ \\
\hline & $<0.001$ & & $<0.001$ & 0.03 \\
\hline
\end{tabular}
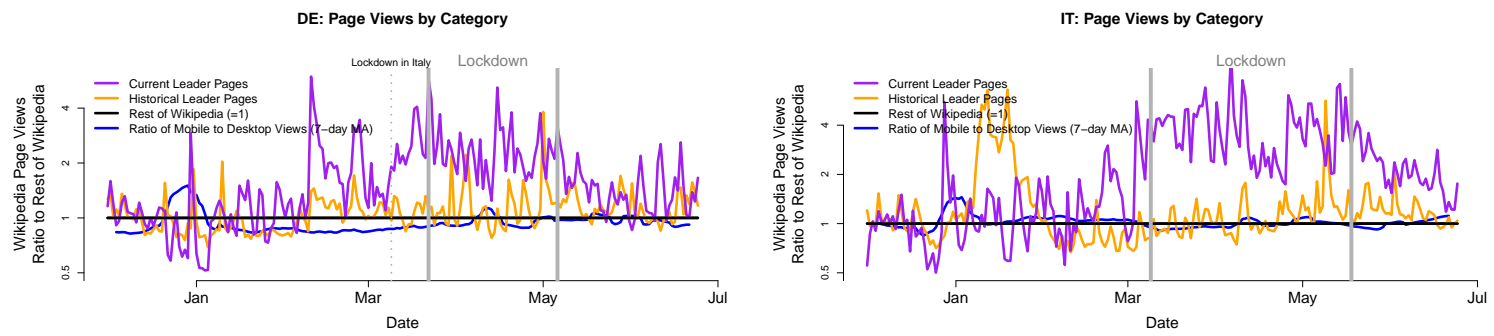

Note: Incidence rate ratios shown above are from a negative binomial regression estimating the daily number of views within a category in the lockdown period compared to December 2019 relative to the number of views across the rest of Wikipedia compared to December 2019 (using the same difference-in-difference specification as the Twitter follower analysis).

Observations are the total views per category by day. $95 \%$ confidence intervals are shown in parentheses, and p-values are shown in the third row for each language. See the SI for over-time ratios by day for all comparison languages (Figure A6), and for the dates of the lockdowns used (Table A4). German and Italian pages of historical leaders (shown in orange in the figures above) saw several large and short-lived spikes in views not clearly related to those countries' lockdowns. 


\section{Conclusion}

Crisis in highly censored environments creates a gateway to sensitive, censored information unrelated to the crisis. Like in democracies, consumers of information in autocracies seek out information and depend more on the media during crises. However, in highly censored environments, increased information seeking also incentivizes censorship circumvention. This new ability to evade censorship allows users to discover a wider variety of information than they may have initially sought.

While the results do not link this gateway in the case of the coronavirus crisis to the political fortunes of the Chinese government, they do suggest that crisis may be additionally sensitive in highly censored environments because it can undermine censorship. While in normal times censorship may be highly effective, it may create unintended side effects during crisis. 


\section{References}

Adena, Maja, Ruben Enikolopov, Maria Petrova, Veronica Santarosa and Ekaterina Zhuravskaya. 2015. "Radio and the Rise of the Nazis in Prewar Germany." The Quarterly Journal of Economics 130(4):1885-1939.

Albertson, Bethany and Shana Kushner Gadarian. 2015. Anxious politics: Democratic citizenship in a threatening world. Cambridge University Press.

Althaus, Scott L. 2002. “American news consumption during times of national crisis." PS: Political Science and Politics 35(3):517-521.

Ball-Rokeach, Sandra J and Melvin L DeFleur. 1976. "A Dependency Model of Mass-Media Effects." Communication Research 3(1):3-21.

Bar-Ilan, Judit and Ana Echermane. 2005. "The anthrax scare and the Web: A content analysis of Web pages linking to resources on anthrax." Scientometrics 63(3):443-462.

Boxell, Levi and Zachary Steinert-Threlkeld. 2019. "Taxing dissent: The impact of a social media tax in Uganda.".

Cao, Qitong. 2020. "The Limitations of Internet Censorship for Authoritarian Information Control:Evidence from China." Working Paper.

Chen, Yuyu and David Y Yang. 2019. "The Impact of Media Censorship: 1984 or Brave New World?" American Economic Review 109(6):2294-2332.

Deibert, Ronald, John Palfrey, Rafal Rohozinski and Jonathan Zittrain. 2011. Access Contested: Security, Identity, and Resistance in Asian Cyberspace. Cambridge: MIT Press.

Enikolopov, Ruben, Maria Petrova and Ekaterina Zhuravskaya. 2011. "Media and Political Persuasion: Evidence from Russia." American Economic Review 101(7):3253-3285.

Gläßel, Christian and Katrin Paula. 2019. "Sometimes less is more: Censorship, news falsification, and disapproval in 1989 East Germany." American Journal of Political Science .

Hassanpour, Navid. 2014. "Media disruption and revolutionary unrest: Evidence from Mubarak's quasiexperiment." Political Communication 31(1):1-24.

Hirschburg, Peter L, Don A Dillman and Sandra J Ball-Rokeach. 1986. "Media system dependency theory: Responses to the eruption of Mount St. Helens." Media, audience, and social structure pp. 117126.

Hobbs, William R and Margaret E Roberts. 2018. "How sudden censorship can increase access to information." American Political Science Review 112(3):621-636.

Huang, Haifeng. 2015. "Propaganda as Signaling.” Comparative Politics 47(4):419-444.

Jansen, Sue Curry and Brian Martin. 2003. "Making Censorship Backfire.” Counterpoise 7(3):5-15.

Kim, Yong-Chan, Joo-Young Jung, Elisia L Cohen and Sandra J Ball-Rokeach. 2004. "Internet connectedness before and after September 11 2001." New media \& society 6(5):611-631.

Loveless, Matthew. 2008. "Media Dependency: Mass Media as Sources of Information in the Democratizing Countries of Central and Eastern Europe." Democratization 15(1):162-183.

MacKinnon, Rebecca. 2012. Consent of the Networked: The Worldwide Struggle For Internet Freedom. New York: Basic Books. 
MacKuen, Michael, Jennifer Wolak, Luke Keele and George E Marcus. 2010. "Civic engagements: Resolute partisanship or reflective deliberation." American Journal of Political Science 54(2):440 458.

Marcus, George E and Michael B MacKuen. 1993. "Anxiety, enthusiasm, and the vote: The emotional underpinnings of learning and involvement during presidential campaigns." American Political Science Review pp. 672-685.

Marcus, George E, W Russell Neuman and Michael MacKuen. 2000. Affective Intelligence and Political Judgment. Chicago: University of Chicago Press.

Morozov, Evgeny. 2011. The Net Delusion: The Dark Side of Internet Freedom. New York: PublicAffairs.

Nabi, Zubair. 2014. "Censorship is futile.” First Monday 19(11).

Nazeri, Nima and Collin Anderson. 2013. "Citation Filtered: Iran's Censorship of Wikipedia." Iran Media Program .

Pan, Jennifer and Alexandra A Siegel. 2020. "How Saudi crackdowns fail to silence online dissent." American Political Science Review 114(1):109-125.

Roberts, Margaret E. 2018. Censored: Distraction and Diversion inside China's Great Firewall. Princeton University Press.

Sanovich, Sergey, Denis Stukal and Joshua A Tucker. 2018. "Turning the virtual tables: Government strategies for addressing online opposition with an application to Russia." Comparative Politics 50(3):435-482.

Steinert-Threlkeld, Zachary C. 2017. "Longitudinal Network Centrality Using Incomplete Data." Political Analysis 25:308-328.

Stockmann, Daniela. 2012. Media Commercialization and Authoritarian Rule in China. Cambridge: Cambridge University Press.

Stockmann, Daniela and Mary E Gallagher. 2011. "Remote Control: How the Media Sustain Authoritarian Rule in China." Comparative Political Studies 44(4):436-467.

Tai, Zixue and Tao Sun. 2007. "Media dependencies in a changing media environment: The case of the 2003 SARS epidemic in China." New Media \& Society 9(6):987-1009.

Yanagizawa-Drott, David. 2014. "Propaganda and conflict: Evidence from the Rwandan genocide." The Quarterly Journal of Economics 129(4):1947-1994. 
Supplementary Materials for

"Crisis is a Gateway to Censored Information" 


\section{S1 Twitter Activity by Province}

Figure A1 shows the number of unique, geo-locating users who are tweeting in Chinese by province. The $\mathrm{x}$-axis is the number of months before (negative) or after (positive) the initial coronavirus lockdown in Hubei province. The blue line is a pre-lockdown average for $\mathrm{x}$ less than 0 and a five term polynomial regression for $\mathrm{x}$ greater than or equal to 0 (where 0 is the first day of provincial lockdown). The points in Figure 2 are the values of the blue line by province for $x$ equals $1 / 30$ (first day of lockdown) and $x$ equals 1 (day 30 of lockdown).

Figure A1: Increases in Geo-Located Twitter Activity by Province (modeled)

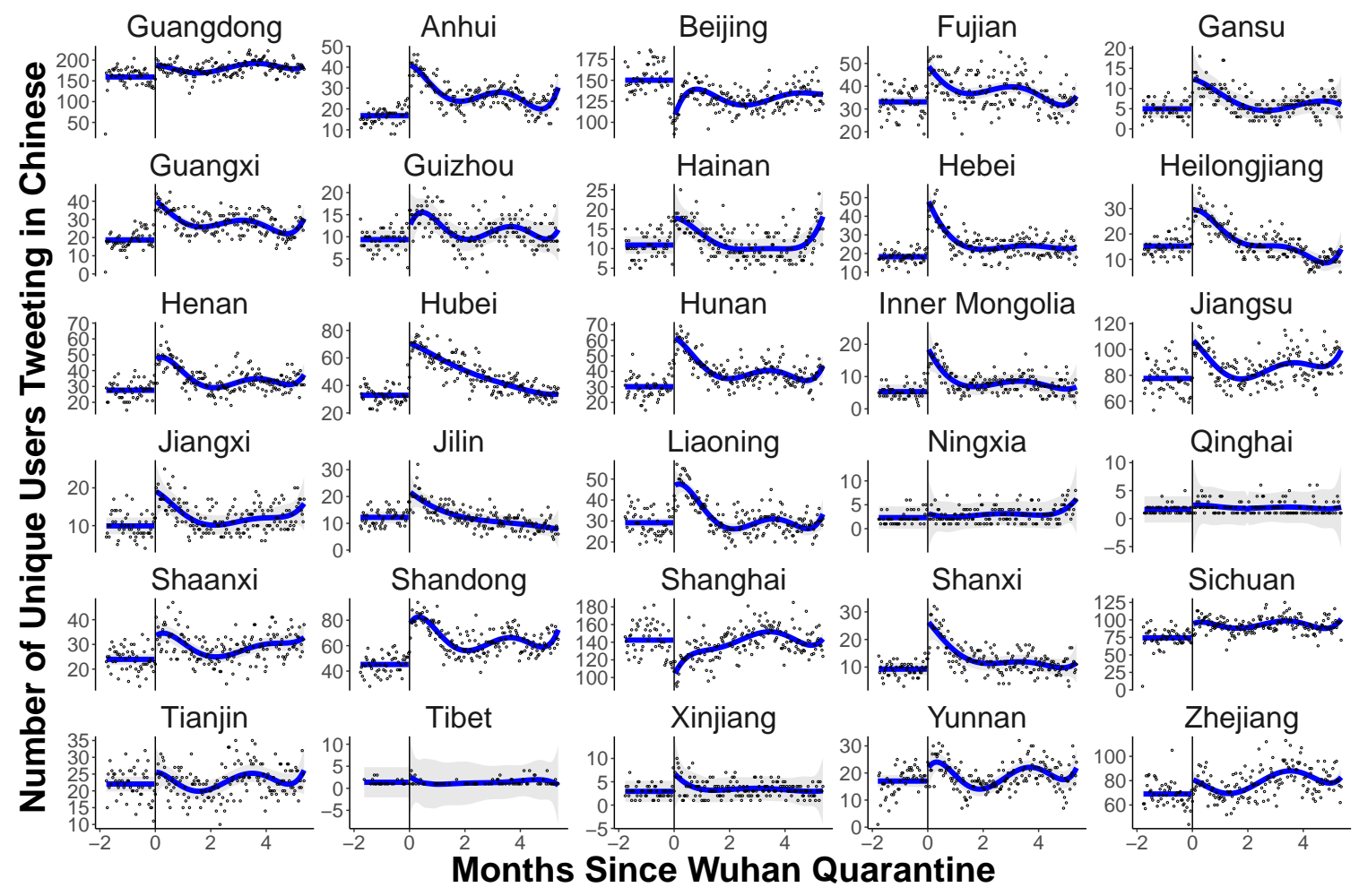




\section{S2 Twitter Data Detail}

From a global sample of tweets with GPS coordinates, we found the 1,448,850 from China from December 1, 2019 through June 30, 2020, 367,875 of which are in Chinese. This corpus contains 101,553 unique users, 43,114 of which are in Chinese. We sample 5,000 of these 43,114. These dates were chosen to encompass a baseline period and the height of Covid-19 in China.

For these 5,000 random users in China, we download who they follow, their "friends" in Twitter parlance. From these friends, we identify the 5,000 most common accounts that are either a Chinese language account or has Chinese characters in their name or description field. Of these 5,000 most common friends, we keep the 354 non-porn accounts and sample 200 from the remaining 4,646 porn accounts.

We then download the followers of these 554 accounts. For each of these $38,050,454$ total followers, we identify the location of the users. Because very few of these followers have geolocated information, we rely on the language of their Twitter status and their self-reported location to distinguish between mainland and overseas followers. We only include users whose status language is Chinese to rule out the possibility that foreigners are following these accounts. Followers are classified as Mainland Chinese if the location field contains the name of a Chinese city, town, or province. Followers are classified as from Hong Kong if the location field contains the name of a district in Hong Kong. Followers are classified as Taiwanese if the location field contains the name of a Taiwanese city, county, or district. Followers are classified as US if if the location field contains the name of states or state abbreviations (in capital letters).

\section{S3 Robustness Checks}

We are interested in whether the result is driven by (1) a misspecified treatment period, (2) the choice of comparison group, and (3) an increase of followers due to only a few accounts.

Figure A2 plots the estimates based on regressions for each week before and after the lockdown. We do not see pre-treatment increases in number of followers in China, and the increase starts precisely on the week of lockdown.

Figures A3 and A4 verify that the results in Figure 5 are not due to choosing Hong Kong for the denominator. Figure A3 uses accounts from Taiwan for the denominator, and Figure A4 uses accounts in the United States. These accounts are from any user using Chinese and their self-reported location is in Taiwan or the United States. Figure A5 reports the regression estimate for the relative ratio of number 
Figure A2: Increases in Twitter Followers from mainland China versus Hong Kong by Week Relative Size of New Followers by Week, China / Hong Kong

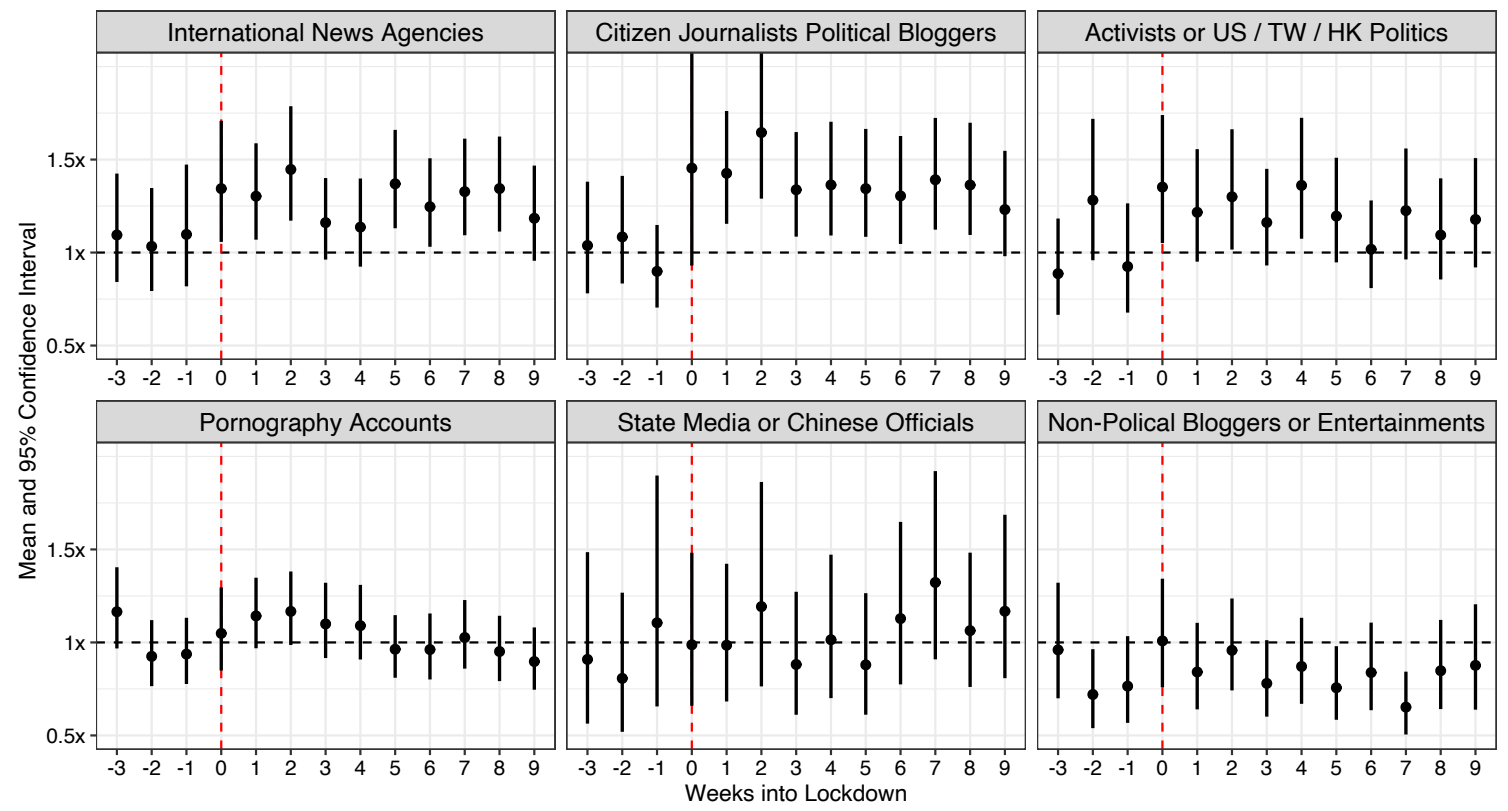

Note: Incidence rate ratios shown above are from Negative Binomial regressions of number of daily new followers on the interaction between dummy for each week and China, with December 2019 as control period and Hong Kong as control group.

of new followers (akin to a Difference-in-differences design with December 2019 as control period and Hong Kong/Taiwan/China as control group). The result is not driven by Hong Kong-specific trend of news cycles.

Table A1 shows accounts in each category with the greatest gain in relative followers. We can see that the result is not driven by only a few accounts. 
Figure A3: Increases in Twitter Followers from China versus Taiwan

New Followers Compared to Baseline, China / Taiwan
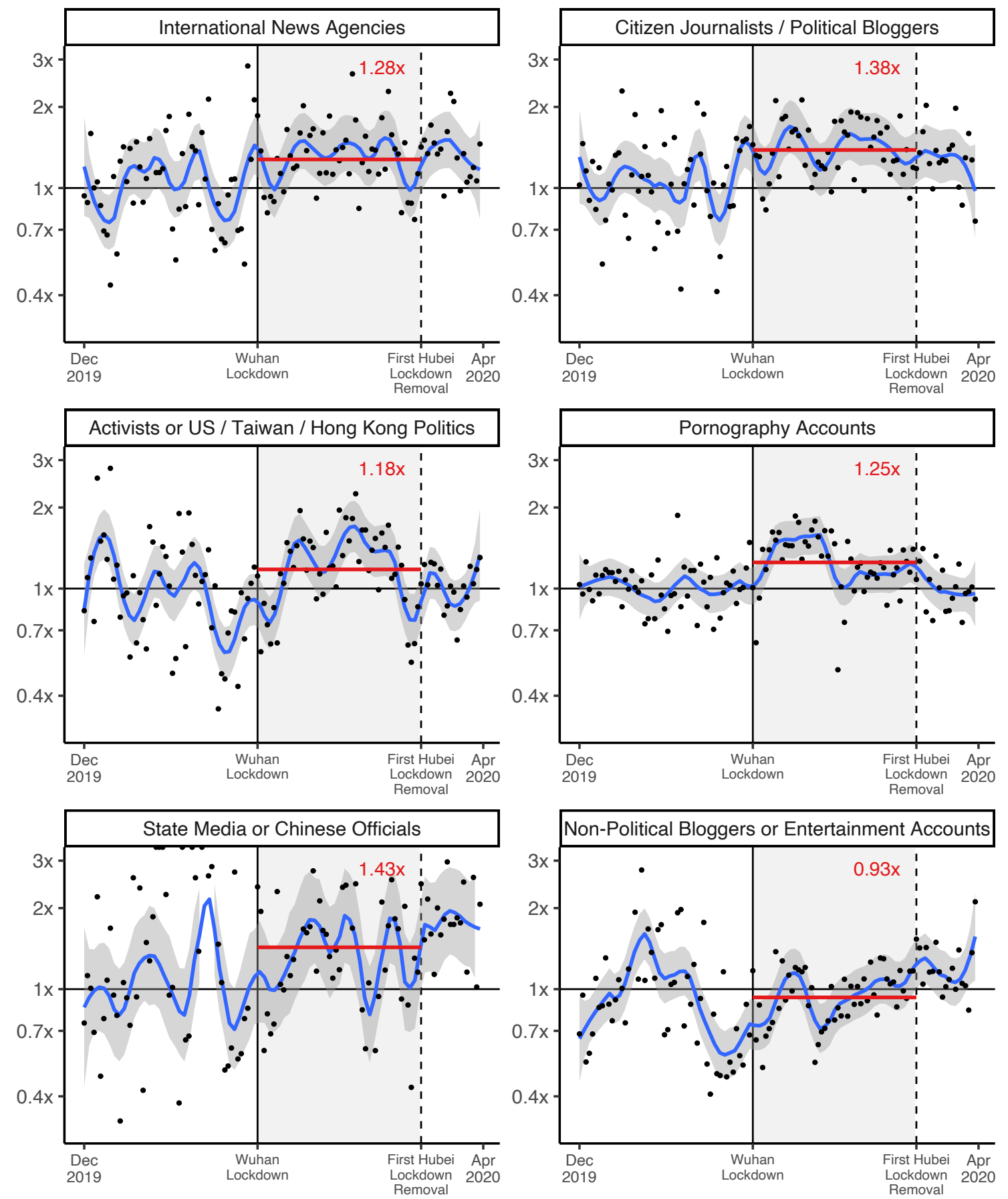

Note: Gain in followers from mainland China compared to Taiwan across six types of popular accounts, relative to December 2019 average. A value greater than 1 means more followers than expected from mainland China than from Taiwan. Accounts creating sensitive, censored information receive more followers than expected once the Wuhan lockdown starts. Fewer Taiwanese users follow Chinese state media or government officials than Hong Kong users do. 
Figure A4: Increases in Twitter Followers from China versus US

\section{New Followers Compared to Baseline, China / US}
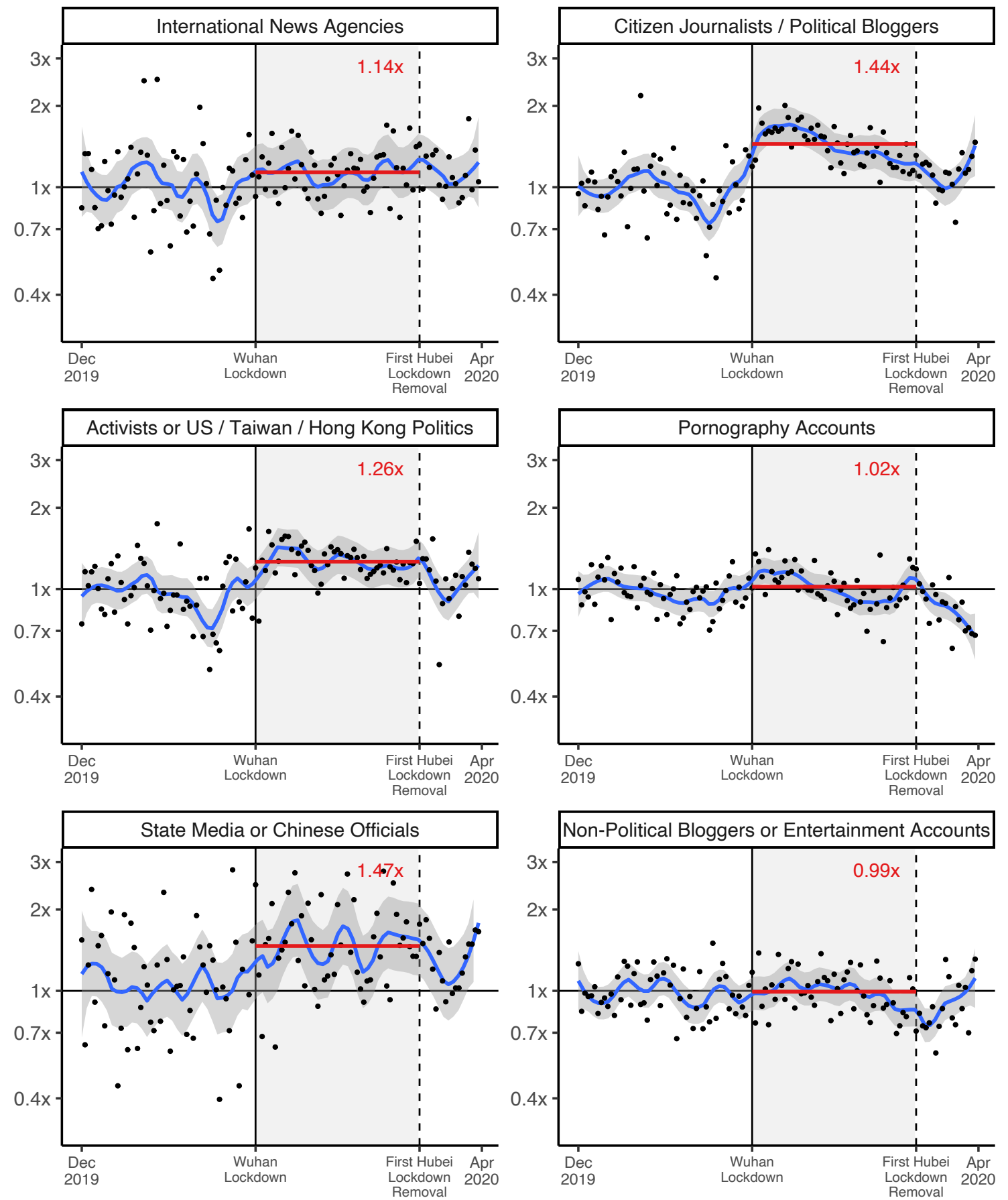

Note: Gain in followers from mainland China compared to US across six types of popular accounts, relative to December 2019 average. A value greater than 1 means more followers than expected from mainland China than from the US. Accounts creating sensitive, censored information receive more followers than expected once the Wuhan lockdown starts. Fewer US users follow Chinese state media or government officials than Hong Kong users do. 
Figure A5: Increases in Twitter Followers from China versus Others (Regression Estimate) Relative Size of New Followers, China / Control Group

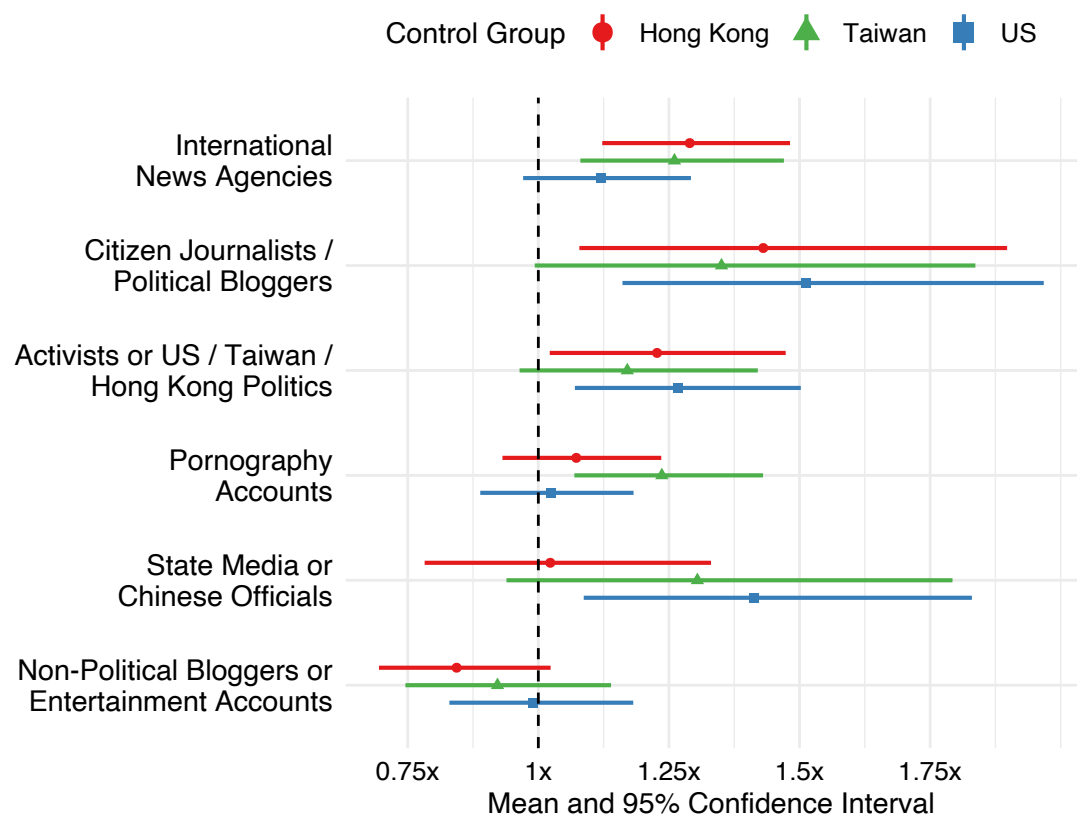

Note: Incidence rate ratios shown above are from negative binomial regressions of number of new followers on the interaction between indicator variables for 'in lockdown period' and 'in mainland China', with December 2019 as the control period. 


\begin{tabular}{|c|c|c|}
\hline Account Screen Name & Account Name & China/HK \\
\hline \multicolumn{3}{|c|}{ International News Agencies } \\
\hline VOAHK & 美国之音香港 & 1.88 \\
\hline mingpaocom & 明報即時新聞 & 1.58 \\
\hline TW_nextmedia & 蘋果新聞網 Taiwan News & 1.58 \\
\hline ABC̄Chinese & $\mathrm{ABC}$ 中文 & 1.57 \\
\hline rthk_news & 香港電台新聞頻道 & 1.57 \\
\hline RFI_TradCn & RFI 華語 - 法國國際廣播電台 & 1.49 \\
\hline initiumnews & 端傳媒 Initium Media & 1.47 \\
\hline ReutersCN & Reuters 路透中文 & 1.38 \\
\hline appledaily_hk & 香港蘋果日報 & 1.37 \\
\hline RFA_Chinese & 自由亚洲电台 & 1.35 \\
\hline \multicolumn{3}{|c|}{ Citizen Journalists / Political Bloggers } \\
\hline badiucao & 巴丢草 Badiucao & 5.23 \\
\hline TWSHASH1 & 台湾件事 & 3.69 \\
\hline RFAChinese & R(ebel)RFAChinese & 3.11 \\
\hline 709liwenzu & 李文足（王全璋妻子） & 2.57 \\
\hline chenqiushi404 & 陈秋实（陳秋實） & 1.98 \\
\hline DongFang_USA & 东方 & 1.83 \\
\hline SoundofHopeSOH & 希望之聲國際廣播電台 & 1.74 \\
\hline RealHaonian & Real 辛影年 & 1.73 \\
\hline ttingxiao & 小婷 & 1.72 \\
\hline LifetimeUSCN & LIFETIME 視界 & 1.68 \\
\hline \multicolumn{3}{|c|}{ Activists or US / Taiwan / Hong Kong Politics } \\
\hline aiww & 艾未末 Ai Weiwei & 3.02 \\
\hline wentommy & 文涛 & 2.55 \\
\hline weiquanwang & 维权网 & 2.40 \\
\hline WEI_JINGSHENG & Wei Jingsheng 魏京生 & 2.35 \\
\hline hrw_chinese & 人权观察 HRW Chinese & 2.29 \\
\hline lianchaohan & 韩连潮 & 2.21 \\
\hline kungat & 贡噶扎西 KUNGA TASHI & 2.15 \\
\hline zhiyongxu & 许志永 & 2.13 \\
\hline XiaYeliang & 夏業良 & 2.08 \\
\hline yangjianli001 & 楊建利 Yang Jianli & 2.05 \\
\hline \multicolumn{3}{|c|}{ State Media or Chinese Officials } \\
\hline HuXijin_GT & Hu Xijin 胡锡进 & 1.47 \\
\hline Echinanews & China News 中国新闻网 & 1.34 \\
\hline PDChinese & 人民日報 People’s Daily & 1.04 \\
\hline XinhuaChinese & New China 中文 & 0.78 \\
\hline \multicolumn{3}{|c|}{ Non-Political Bloggers or Entertainment Accounts } \\
\hline xiashuidaojun & 下水道 & 1.69 \\
\hline scavin & scavin & 1.52 \\
\hline cnliziqi & 李子染 & 1.42 \\
\hline Norathen & Freaky & 1.41 \\
\hline KyouKyouu & 温和女推友姜姜 & 1.38 \\
\hline corvuschen & 陈尔冬是你大爷 & 1.36 \\
\hline caijingxiang & 财经真相 & 1.31 \\
\hline williamlong & 月光博客 & 1.28 \\
\hline warmche & 废物甜心 & 1.21 \\
\hline ShanePricila & 锦瑟 & 1.16 \\
\hline
\end{tabular}

Table A1: Top Relative Increase in Twitter New Followers at Account-Levels, China vs. Hong Kong (Excluding Pornography Accounts)

Note: Incidence rate ratios shown above are from the averages of weekly new followers during lockdown period relative to December 2019, with China in the numerator and Hong Kong in the denominator. 


\section{S4 Wikipedia Page-by-Page Analyses and Country Comparisons}

Page view data analyzed in this paper is publicly available and hosted here: https : //dumps . wikimedia. org/other/pagecounts-ez/merged/. In replication materials, we will additionally provide processed and aggregated versions of the page view data so that this paper's findings can be more quickly replicated than would be possible with the above page view files.

Below, we show the top Wikipedia pages by relative and absolute increases in page views within each of the categories we analyzed in the main text, as well as pages about the coronavirus and COVID19 (pages considered: coronavirus, COVID-19, ventilator, flu, pneumonia, fever). The largest relative increases among these pages and for current leaders were related to coronavirus - the COVID-19 pandemic Wikipedia page and the head of China's National Health Commission. Top increases for pages that were blocked prior to the introduction of https on Wikipedia (after which China blocked all pages) were for an activist who criticized China's pandemic response. 


\begin{tabular}{llll} 
Overall & Blocked & Current Leaders & Historical Leaders \\
\hline 马晓伟_(官员) (36.67) & 许志永 (16.78) & 马晓伟_(官员) (36.67) & 胡锦涛 (1.81) \\
Ma Xiaowei & Xu Zhiyong & Ma Xiaowei & Hu Jintao \\
许志永 (16.78) & 2 月 17 日 (9.01) & 孙春兰 (9.38) & 邓小平 (1.75) \\
Xu Zhiyong & February 17 & Sun Chunlan & Deng Xiaoping \\
孙春兰 (9.38) & 西藏人民起义日 (7.04) & 李克强 (2.52) & 江泽民 (1.65) \\
Sun Chunlan & Tibetan Uprising Day & Li Keqiang & Jiang Zemin \\
2月 17 日 (9.01) & 台湾 (5.21) & 王岐山 (2.50) & 华国锋 (1.44) \\
February 17 & Taiwan & Wan Qishan & Hua Guofeng \\
西藏人民起义日 (7.04) & 圆周率日 (4.15) & 肖捷 (2.45) & 毛泽东 (1.15) \\
Tibetan Uprising Day & Pi Day & Xiao Jie & Mao Zedong \\
肺炎 (5.38) & 艾未未 (3.93) & 韩正 (2.14) & \\
Pneumonia & Ai Weiwei & Han Zheng & \\
台湾 (5.21) & 李長春 (3.71) & 胡春华 (1.99) & \\
Taiwan & Li Changchun & Hu Chunhua & \\
流行性感冒 (5.04) & 新唐人电视台 (3.51) & 苗圩 (1.88) & \\
Influenza & New Tang Dynasty Television & Miao Wei & \\
圆周率日 (4.15) & 唐柏桥 (3.34) & 习近平 (1.80) & \\
Pi Day & Tang Baiqiao & Xi Jinping & \\
艾未未 (3.93) & 长春围困战 (3.21) & 杨晓渡 (1.73) & \\
Ai Weiwei & Siege of Changchun & Yang Xiaodu & \\
\hline
\end{tabular}

Table A2: Top relative increases for Wikipedia pages January 24 through March 13 compared to December 2019. Note: Labels are limited to: blocked, leader, historical leader, COVID/coronavirus. All other pages are aggregated as "rest of Wikipedia". 


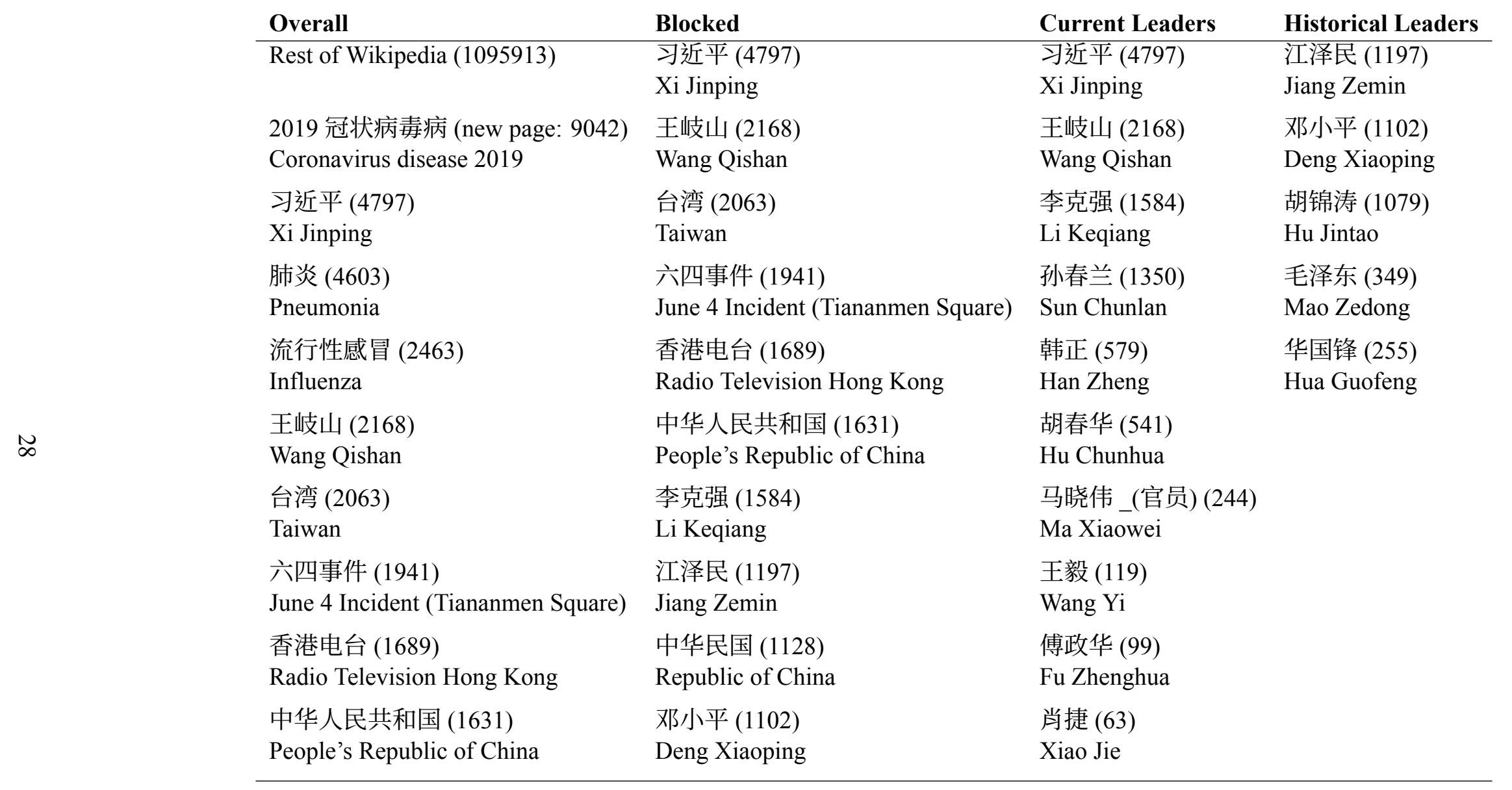

Table A3: Top absolute daily increases for Wikipedia pages January 24 through March 13 compared to December 2019.

Note: Studying average daily increases standardizes the different lengths of time before versus after the Wuhan lockdown. Labels are limited to: blocked, leader, historical leader, COVID/coronavirus. All other pages are aggregated as "rest of Wikipedia". 
In Figure A6, we show the trajectories for categories matching those analyzed for China - current leaders (using offices listed in the CIA World Factbook), historical leaders, and, in Iran, pre-https blocked Wikipedia pages (Nazeri and Anderson, 2013).

Russia, Germany, and Italy (none of which block Wikipedia) saw increases in current leader views without accompanying increases in historical leader views. Germany and Italy did see spikes views of in historical leader pages in the weeks leading up to the relaxation of lockdowns in early May, but saw no change during the initial crisis.

German and Russian political pages also saw an increase in political leader page views prior to their own lockdown, and approximately at the same time as the announcement of widespread lockdown in Italy (see Figure A6).

\begin{tabular}{|c|c|c|}
\hline Country & Lockdown Start Lockdown End & Historical Leaders \\
\hline China & $\begin{array}{c}\text { January 24, } 2020 \text { March 13, } 2020 \\
\text { Hubei Lockdown }\end{array}$ & Paramount Leader \\
\hline Iran & $\begin{array}{c}\text { March 20, } 2020 \quad \text { April 18, } 2020 \\
\text { Nowruz - Tehran Easing }\end{array}$ & President, Supreme Leader \\
\hline Russia & $\begin{array}{c}\text { March 28, } 2020 \quad \text { May 12, } 2020 \\
\text { Non-Working Period }\end{array}$ & $\begin{array}{l}\text { President } \\
\text { General Secretary (Soviet Union) } \\
\text { Chairman, Council of Ministers (1953) }\end{array}$ \\
\hline Germany & $\begin{array}{c}\text { March 22, } 2020 \quad \text { May 6, } 2020 \\
\text { National Social Distancing }\end{array}$ & Chancellor \\
\hline Italy & $\begin{array}{c}\text { March 9, } 2020 \quad \text { May 18, } 2020 \\
\text { National Quarantine }\end{array}$ & Prime Minister \\
\hline
\end{tabular}

Table A4: Lockdown dates

Note: This table lists the time periods we use to estimate the effects of crisis lockdowns on Wikipedia page views, along with the offices considered for the historical leaders analysis. Each country's lockdown involved various levels of lockdown for different parts of the countries, and so there is no single time period for us to analyze. Figure A6 displays Wikipedia page views with solid, vertical gray lines for the periods listed above. 

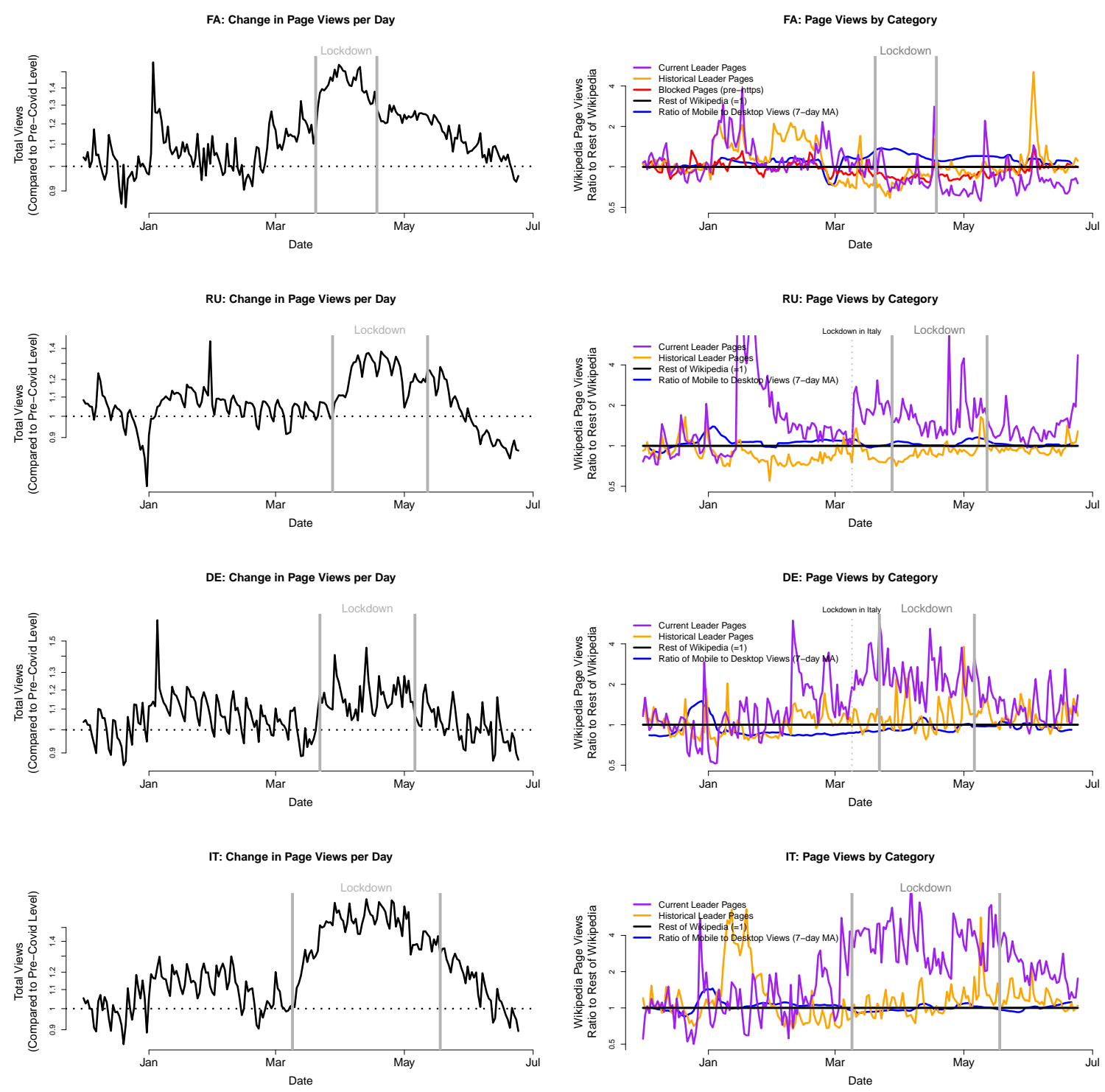

Figure A6: Views of Blocked, Current Leader, and Historical Leader Wikipedia Pages in Other Countries 